\title{
Proximate nutritional composition and heat-induced changes of starch in selected grains and seeds\#
}

\author{
Radka Vrancheva1, Loutcian Krystev², Aneta Popova³, Dasha Mihaylova ${ }^{4 *}$ \\ ${ }^{1}$ Department of Analytical chemistry and Physical chemistry, University of Food Technologies, 26, Maritsa Blvd., 4002, Plovdiv, Bulgaria, \\ ${ }^{2}$ Center for Research Projects and Transfer of Technologies, University of Food Technologies, 26 Maritza Blvd., Plovdiv, 4002, ${ }^{3}$ Department of \\ Catering and tourism, University of Food Technologies, 26, Maritsa Blvd., 4002, Plovdiv, Bulgaria, ${ }^{4}$ Department of Biotechnology, University of \\ Food Technologies, 26, Maritsa Blvd., 4002, Plovdiv, Bulgaria
}

\section{A B S TR A C T}

\begin{abstract}
Grains are cultivated worldwide and comprise a big percentage of the world's daily meals being at the base of the Food Guide Pyramid. Whole grains provide a wide range of nutrients and phytochemicals that optimize health. In the present study commercially available samples of eight grain and seed species (chia, common oat, proso millet, amaranth, quinoa, buckwheat, linseed, and einkorn) were studied in respect of their nutritional composition - dry matter, ash, macro-and microelement content, crude protein and fatty acid composition. The paper lies on the following methods: AACC, AOAC Official methods, ISO procedures, spectrometry and light microscopy. The dry matter content in the grains ranged from $87.91 \%$ to $94.39 \%$, whereas the ash was from $1.24 \%$ to $3.29 \%$. The analysis of the mineral content shows the predominant content of $\mathrm{K}, \mathrm{Mg}, \mathrm{P}$ and $\mathrm{Ca}$. The palmitic acid, stearic acid, oleic acid, linoleic acid and arachidic acid were the most abundant fatty acids of the evaluated ones. The crude protein content varied between $12.73 \%$ in common oat and $23.72 \%$ in chia. The established ash content among the investigated grains ranged from $1.24 \%$ to $3.29 \%$. The results obtained revealed the nutritional content and the potential health effects of selected commercially available grains and pointed out their possible application in culinary. The consumption of a variety of whole grains ensures more health-promoting nutrients, as well as makes meals more attractive.
\end{abstract}

Keywords: Grains; Seeds; Nutritional composition; Health-promoting nutrients

\section{INTRODUCTION}

Food is the main energy source for the human body and it needs nutritious food to be healthy. Food is basically being considered as a macro- (carbohydrates, proteins, and fats) and micro- (vitamins and minerals) nutrient source. While macronutrients are principally energy contributors, micronutrients are responsible for many of the body's biochemical processes. The full spectrum of essential minerals is critically important to the maintenance of human health. The diets of most people nowadays fall far short of the current dietary recommendations. Dietary recommendations advocate for greater whole grain consumption while limiting refined grains in the diet. MyPlate conception of nutrient-dense foods are defined as foods that provide substantial amounts of vitamins, minerals and other nutrients with relatively few calories. Given the current dietary trends, the nutrient density approach can be a valuable tool for nutrition education and dietary guidance. In recent years, consumers are becoming more diverse when choosing foods to consume. The consumer's decision to accept or reject a certain food has been to object of marketing analysis for a certain timeline. It has been suggested that characteristics such as nutritional composition, gender, age, cultural and religious habits, etc. influence the consumer's final decision (Leng et al., 2017). Food producers are constantly competing in new product development in order to meet the consumer's expectations and demands, as well as to provide nutritious products. Nowadays, consumers are aware of factors like safety, quality, and nutritional status, and are very selective when it comes to fair trade and sustainable production (Vermier and Verbeke, 2006). Nutrient profiling is defined as the "science of classifying or ranking foods according to their nutritional composition for reasons related to preventing of disease and promoting health" (WHO, 2010).

\footnotetext{
\#Abstract has been published in the $3^{\text {rd }}$ International Congress on Food Technology; October 10-12, 2018 Nevşehir/Turkey. *Corresponding author:

Dasha Mihaylova, Department of Biotechnology, University of Food Technologies, 26, Maritsa Blvd., 4002, Plovdiv, Bulgaria.

E-mail: dashamihaylova@yahoo.com
}

Received: 02 May 2019; Accepted: 02 September 2019 
Exactly nutrient profiling enables the classification of foods according to their nutritional composition (Verhagen and Van Den Berg, 2008). Worldwide, the number of nutrition policy applications and the different nutrient-profiling models has made nutrient profiling importance increased rapidly in recent years (Stockley et al., 2004).

Modern nutritional trends require continuous improvement of existing recipes in order to achieve healthier products. The diversification of culinary products with new or modified products consisting of natural ingredients containing biologically active compositions with proven beneficial effects responds to the growing consumer demand. Cereal and pseudo-cereal crops offer the opportunity to create culinary products with a healthy effect thanks to their phenolic acids, flavonoids, vitamins and others as valuable ingredients in the preparation of a variety of dishes. The proven high antioxidant activity of proso millet, buckwheat, quinoa, linseed, amaranth and chia, as well as the total polyphenols and elemental composition make them attractive for inclusion in salads in order to enrich their valuable ingredients.

Starch is the primary source of energy in cereal grains. It has some unique properties and greatly contributes to food product functionality. Its major components are amylopectin and amylose. Amylose is an essentially linear polymer of starch composed of $\alpha$-1,4-linked $\mathrm{D}$-glucopyranose molecules and amylopectin is a large, branched, D-glucopyranose polymer of starch containing both $\alpha-1,4$ and $\alpha-1,6$ linkages.

The amylose/amylopectin ratio differs among starches, but typical levels of amylose and amylopectin are between 25-75\% (Hung et al., 2006). The irreversible changes taking place on heating are commonly denominated by gelatinization and depending on its conditions, i.e. starch type, concentration, time-temperature, etc. large differences in the extent of granule swelling may be obtained (Svegmark and Hermansson, 1991).

Existing research on the topic of grains and seed focuses not only, on their physicochemical characteristics, but also biological activity and possible application. Authors profile one or several grains/seeds in terms of both animal and human nutrition (Graf et al., 2015; Beloshapka et al., 2016). Grains are quite often found as ingredients of pet foods (Beaton, 2014). Stamatovska et al. (2018) point out the possibility of ingredient substitutions in different bakery products.

The purpose of this study was to investigate the nutritional value of six grain and two seed species in terms of crude protein, moisture, ash, fatty acid composition and mineral content and to provide data in order to update the existing nutrient profile of the studied samples. The differences of heat-induces changes of starch were also described in the view of the possible application in the food production industry.

\section{MATERIALS AND METHODS}

\section{Chemicals and reagents}

All reagents used in this study were of analytical grade and purchased from Merck Chemicals, Sigma-Aldrich (Germany), Cheminova (France).

\section{Plant materials and extracts preparation}

Commercially available samples of eight species (chia, common oat, proso millet, amaranth, quinoa, buckwheat, linseed, and einkorn) were obtained from the local market in Plovdiv (Bulgaria) in spring 2018. The samples were milled into flour to obtain homogenous particle size. Sample extraction $(10 \mathrm{~g})$ was performed for $24 \mathrm{~h}$ by stirring with methanol $(50 \mathrm{~mL})$ at $25^{\circ} \mathrm{C}$ and $150 \mathrm{rpm} /$ agitation, finally filtered through Whatman No. 4 paper. The procedure was repeated twice as the second extraction was carried out with $30 \mathrm{~mL}$ solvent. The extracts were pooled together and stored in refrigerator for further analyses.

\section{Nutritional analysis \\ Moisture}

Total moisture content of the samples was determined according to the procedure described in AACC (2000) method 44-15A.

\section{Ash content}

Ash content of the samples was determined according to the AOAC Official Method 942.05 (2003).

\section{Crude protein content}

Crude protein content was estimated by Kjeldahl's method according to AOAC Official method 979.09 (2005).

\section{Fatty acid composition}

The fatty acid composition was estimated according to ISO 12966-2:2017 (2017) method by GC 17A Shimadzu instrument equipped with FID detector using a $30 \mathrm{mx}$ $0.32 \mathrm{~mm}$ id, $1 \mu \mathrm{m}$ Stabilwax - DA (fused silica) column (Restek, USA). The extraction of the fatty acids is carried out by means of diethyl ether in a Soxhlet apparatus following AOAC Method 920.39 (2012). The fatty acids methyl esters (FAMEs) were prepared in accordance with ISO 12966-2:2017 (2017).

\section{Mineral content}

An inductively coupled plasma quadrupole mass spectrometer ICP-MS Agilent 7700 (Tokyo, Japan) 
with octopole reaction system (He collision gas flow $4.0 \mathrm{~mL} / \mathrm{min}$ ) was used for macro- and microelements concentrations evaluations using Thermo Scientific iCAP 6300 ICP Spectrometer.

\section{Light microscopy of starch dispersions}

The microstructure of the starch dispersions was assessed by light microscopic assay using a method adapted from Langton and Hermansson (1989). Two percent starch dispersions were prepared with distilled water and heated in a water bath in a range of $65-80{ }^{\circ} \mathrm{C}$. The samples were examined with a Celestron LCD Digital II microscope. Micrographs were made by means of an 8MP digital camera.

\section{RESULTS AND DISCUSSION}

\section{Crude protein content, moisture and ash}

Proteins are essential biomolecules that play critical roles in the body. In Western diets, protein from plant sources constitutes a lower proportion of protein intake compared to developing nations. The digestibility, amino acid composition, and presence of factors that influence digestibility are the major differences between plant and animal protein sources. However, contrary to popular belief, protein from plant sources can meet human protein needs (McEvoy et al., 2012). Data concerning crude protein, moisture and ash content in the analyzed grains and seeds is presented in Table 1.

Crude protein content is reported to have a positive and significant correlation with root density (Präger et al., 2018). The currently investigated quinoa has $13.34 \%$ crude protein, which is in accordance with the stated percentage between 11 and 15 from Guzman-Maldonado and ParedesLopez (1998). Among quinoa varieties, ash content is between $2.45 \%$ and $2.61 \%$ and moisture is between $7.31 \%$ and $8.98 \%$ (Repo-Carrasco-Valencia and Serna, 2011) that is significantly different compared to the data established in this study $(12.09 \%$ moisture and $3.27 \%$ ash). This is probably due to the variety specifics of the particular grains and seeds and the various environment conditions

\begin{tabular}{|c|c|c|c|}
\hline Sample & Crude protein & Moisture & Ash content \\
\hline Quinoa & 13.34 & 12.09 & 3.27 \\
\hline Proso millet & 13.69 & 10.57 & 1.24 \\
\hline Common oat & 12.73 & 10.75 & 3.29 \\
\hline Buckwheat & 13.26 & 7.21 & 1.88 \\
\hline Einkorn & 18.91 & 11.05 & 2.64 \\
\hline Amaranth & 18.56 & 8.88 & 3.23 \\
\hline Linseed & 23.55 & 5.61 & 2.62 \\
\hline Chia & 23.72 & 7.17 & 3.20 \\
\hline
\end{tabular}

(growing conditions, local climatee, etc.). The protein content of amaranth (18.56\%) recorded in the present study was higher than the values reported by Palombini et al. (2013) while the ash content corresponded well to the results published by the same authors. The protein content in buckwheat documented by Eggum et al. (1980) was approximately $12 \%$ and thus very much the same as in wheat. The currently investigated buckwheat sample contained $13.26 \%$ crude protein and $1.88 \%$ ash.

The least protein value $12.73 \%$ was reported for common oat. Similar variations in the protein and ash content of proso millet have been reported by Kalinova and Moudry (2006). The highest protein content was found in chia and linseed $23.72 \%$ and $23.55 \%$, respectively. High protein content could be used to fortify diets as a step forward to a more sustainable nutrition.

\section{Fatty acid and mineral composition}

The fatty acid composition ranged from $0.19 \%$ to $67.03 \%$ (Table 2). Among all of the investigated samples, amaranth had higher concentrations of fatty acids.

Linoleic, palmitic, and oleic acids were dominant fatty acids in amaranth samples characterized by Hlinkova et al. (2013). The same results were observed in the current study with the most abundant fatty acid being the palmitic one $(49.96 \%)$. The content of fatty acids in quinoa obtained in the current investigation is relevant to the reported by Palombini et al. (2013). Nitrayová et al. (2014) have documented the fatty acid profile of linseed and chia seeds as follows: linolenic acid constituted on average $54.38 \%$ of the total fatty acids of linseeds and $63.79 \%$ of chia seed, and for linoleic acid it was $15.30 \%$ and $18.89 \%$. The currently established results show a higher content of linolenic acid in chia and lower in linseed. The content of linoleic acid was established to be in a 1:1,23 (chia) and 1:1,29 higher content ratio compared to the results published by Nitrayová et al. (2014). A major part of the composition of fatty acids in einkorn wheat reported by Demir et al. (2015) was linoleic (49.43\%), oleic (34.34\%) and palmitic acid (10.27\%). Similar variations in the fatty acid content of einkorn have been reported in the current study. The main unsaturated fatty acids found in buckwheat by Krumina-Zemture and Beitane (2017) were linoleic and oleic acids, which represented approximately $70 \%$ of the total fatty acids. The established prevalence of linoleic acid in the investigated oat sample as compared to the other cereals is consistent with that reported by Liu (2011).

The most abundant fatty acid documented in the current study was also linoleic acid with $49.57 \%$. The main saturated fatty acids increased cholesterol level in human blood are myristic acid and palmitic acid. The results of this 
Table 2: Fatty acids composition of eight commercially available grains and seeds, $\%$

\begin{tabular}{|c|c|c|c|c|c|c|c|c|}
\hline & Quinoa & Proso millet & Common oat & Buckwheat & Einkorn & Amaranth & Linseed & Chia \\
\hline C12:0 & - & - & - & - & - & - & 0.19 & - \\
\hline C14:0 & 1.17 & - & - & - & - & - & - & - \\
\hline C16:0 & 12.45 & 8.42 & 15.84 & 14.92 & 13.15 & 19.96 & 18.75 & 6.79 \\
\hline C17:0 & - & - & - & - & - & - & 0.26 & - \\
\hline C17:1 & - & - & - & - & - & 0.68 & - & - \\
\hline C18:0 & 2.08 & 2.06 & 1.95 & 2.41 & 1.77 & 2.15 & 1.82 & 2.32 \\
\hline C18:1 & 24.37 & 21.01 & 45.91 & 39.93 & 29.70 & 26.15 & 10.11 & 6.22 \\
\hline C18:2 & 54.48 & 67.64 & 35.55 & 36.78 & 49.57 & 49.90 & 22.78 & 17.64 \\
\hline C18:3 & - & - & - & - & & - & 44.59 & 67.03 \\
\hline C20:0 & 4.32 & 0.87 & 0.75 & 1.63 & 5.81 & 0.97 & 0.54 & - \\
\hline C20:1 & - & - & - & - & - & - & 0.65 & - \\
\hline C20:4 & - & - & - & - & - & - & 0.31 & - \\
\hline $\mathrm{C} 22: 0$ & 1.13 & - & - & 4.33 & - & 0.73 & - & - \\
\hline
\end{tabular}

investigation showed that myristic acid was only determined in the quinoa sample $(1.17 \%)$. The content of palmitic acid in grain and seed samples varied from 6.79 to $19.96 \%$. It is known, that the increased ratio between stearic/palmitic acids and oleic/stearic acids are desirable for the prevention of numerous diseases. The calculated ratio C18:0/C16:0 varied from 0.09 to 0.34 . Evaluation of ratio C18:1/C18:0 showed that chia seeds are healthier than linseed in terms of fatty acid content.

Considering the importance of the body's chemical balance, five macro- and three micro- elements have been identified in the studied samples (Table 3). The most abundant elements were established to be $\mathrm{K}$ and P. Selenium was the lowest presented compound as its highest content was evaluated in the proso millet sample $(0.63 \mathrm{mg} / \mathrm{kg})$.

Several researches have been carried out on the mineral content of chia seeds. Barreto et al. (2016) showed that there are moderate differences in the amounts detected for the studied elements. There is a registered increase in the amount of calcium, and a decrease in the amount of sodium. The potassium, phosphorus, copper, and iron contents are relatively the same.

Palombini et al. (2013) have documented the mineral content of amaranth and quinoa. Similar variations in the studied elements have been evaluated in the present study with the major element in both samples being potassium (4289 $\mathrm{mg} / \mathrm{kg}$ quinoa and $3498 \mathrm{mg} / \mathrm{kg}$ amaranth). Phytic acid corresponds to more than $85 \%$ of the potassium content in cereals, which has a high affinity for hydroxyapatite. The high content of phosphorus in einkorn has also been reported by Abdel-Aal et al. (1995). The same observations have been proven by Rachon et al. (2015). The authors state that phosphorus and potassium are the most abundant elements found in common oat Ciolek et al. (2007). The same results were obtained in the current investigation with $\mathrm{K}$ and $\mathrm{P}$ values being $3000 \mathrm{mg} / \mathrm{kg}$ and $3010 \mathrm{mg} / \mathrm{kg}$,
Table 3: Macro- and microelement content of eight commercially available grains and seeds $(\mathrm{mg} / \mathrm{kg})$

\begin{tabular}{lcccccccc}
\hline Sample/Element & $\mathbf{N a}$ & $\mathbf{K}$ & $\mathbf{M g}$ & $\mathbf{C a}$ & $\mathbf{F e}$ & $\mathbf{P}$ & $\mathbf{C u}$ & $\mathrm{Se}$ \\
\hline Quinoa & 61 & 4289 & 1799 & 364 & 36 & 3850 & 4.2 & $<0.05$ \\
Proso millet & 11 & 2000 & 1120 & 90 & 28 & 2662 & 5.1 & 0.63 \\
Common oat & 16 & 3000 & 1020 & 577 & 31 & 3010 & 3.3 & $<0.05$ \\
Buckwheat & 97 & 2813 & 1320 & 148 & 19 & 2480 & 4.0 & $<0.05$ \\
Einkorn & 74 & 4201 & 1460 & 439 & 48 & 4890 & 6.6 & 0.12 \\
Amaranth & 73 & 3498 & 2550 & 1430 & 69 & 4360 & 5 & 0.14 \\
Linseed & 485 & 8058 & 3650 & 2340 & 52 & 7230 & 14 & 0.14 \\
Chia & 52 & 6146 & 3880 & 7480 & 56 & 7495 & 17 & $<0.05$ \\
\hline
\end{tabular}

respectively. Linseeds are a source of many vitamins and minerals as magnesium and phosphorus (Bernacchia et al., 2014). Relatively the same mineral properties have been documented with $\mathrm{Mg}$ and P values being $3650 \mathrm{mg} /$ $\mathrm{kg}$ and $7230 \mathrm{mg} / \mathrm{kg}$, respectively. The same properties for linseed were recorded by Goyal et al. (2014). Elements found in large quantities in proso millet were phosphorus, potassium, magnesium (Pilat et al., 2016). The obtained data in the current study revealed that proso millet could be a good source of $\mathrm{K}$ and $\mathrm{P}$. Buckwheat is seen as a dietary source of zinc, copper and manganese (Ikeda and Yamashita, 1994). Nedeljković et al. (2014) claim that P and $\mathrm{K}$ were the most abundant elements found in buckwheat flour. This is in accordance with the currently established results for buckwheat.

\section{Heat-induced changes in starch dispersions}

The description and identification of starch constitutes the basic knowledge to develop diverse investigative research and to contribute to the functional properties of starches used in food industry. Two main constituents in different proportions characterize starches: amylose and amylopectin (Table 4).

Microscopic techniques are commonly used to portray the shape and size of starch granules. Starch gelatinization characterizes the transition in granules from an ordered to a disordered state in the presence of water. A number 
of changes i.e. swelling, amylose leakage, and granules disruption are induced by the process of heating in the event of water (Li et al. 2004).

Microstructural changes have been studied as a function of temperature treatment. Samples were taken at various stages of the heat treatment for microstructural evaluation and the reported results illustrate the most significant heat-induced changes. Starch granules represent the first stage of swelling where the release of amylose is limited and its concentration is not high enough to form gel. The starches differed widely in the extent of amylose leaching, degree of swelling, gelatinization transition temperatures. The effect of heating of $2 \%$ starch dispersions to $75^{\circ} \mathrm{C}$ is illustrated in Fig. 1.

Table 4: Starch composition in eight commercially available grains and seeds

\begin{tabular}{|c|c|c|c|}
\hline Variety & Starch, \% & $\begin{array}{c}\text { Amylose } \\
\text { content, \% }\end{array}$ & Reference \\
\hline Quinoa & $53-75$ & $3-20$ & $\begin{array}{l}\text { Li and Zhu (2017); } \\
\text { Wu et al. (2017); } \\
\text { Lindeboom } \\
\text { et al. (2005) }\end{array}$ \\
\hline $\begin{array}{l}\text { Proso } \\
\text { millet }\end{array}$ & $84-85$ & $1-20$ & Kim et al. (39) \\
\hline $\begin{array}{l}\text { Common } \\
\text { oat }\end{array}$ & $55-60$ & 23 & $\begin{array}{l}\text { Hoover and } \\
\text { Senanayake (1996); } \\
\text { Halima et al. (2015) }\end{array}$ \\
\hline Buckwheat & $16-18$ & $21-27$ & Van Hung et al. (2009) \\
\hline Einkorn & $60-61$ & $1-28$ & $\begin{array}{l}\text { Mohammadkhani } \\
\text { et al. (1999) }\end{array}$ \\
\hline Amaranth & $59-60$ & $0.1-11$ & $\begin{array}{l}\text { Becker et al. (1981); } \\
\text { Zhu (2015) }\end{array}$ \\
\hline Linseed & - & - & - \\
\hline Chia & - & - & - \\
\hline
\end{tabular}

There is a variation of the degree of swelling and it is important to state that starch consist of a population of granules with various shapes, deformations etc. dependent of heating. Quinoa samples with higher amylose content tended to a more cohesive, gummy, and chewy texture after cooking (Wu et al. 2017). It is assumed that a higher amylose content may be due to the presence of large-size granules (Kim et al. 2012).

The granules are at the first stage of swelling according to the patterns described by Alcaraz-Alay et al. (2015); Noisuwan et al. (2007); and Tester and Morrison (1990). A number of granules in the second stage of swelling can also be seen in Fig. 1. There are some granules with amylose that has leaked out. From some smears, it is not possible to characterize the exact shape of the starch granules at different stages of swelling. After the thermal treatment, some breakings or conglomerates were noticed on the granules.

By a combination of microscopy techniques, the following observations have been made: the presence of an amyloserich phase in the center of the granules already in the first stage of swelling when the amount of amylose released from the granules is limited.

\section{CONCLUSION}

Proximate composition, minerals and microscopic structure of starch in eight commonly available market grains and seeds have been provided in the present study.

Nutrient content varied widely due to the nature and probably growth conditions on the studied plants. This defines different daily nutrient intake and association

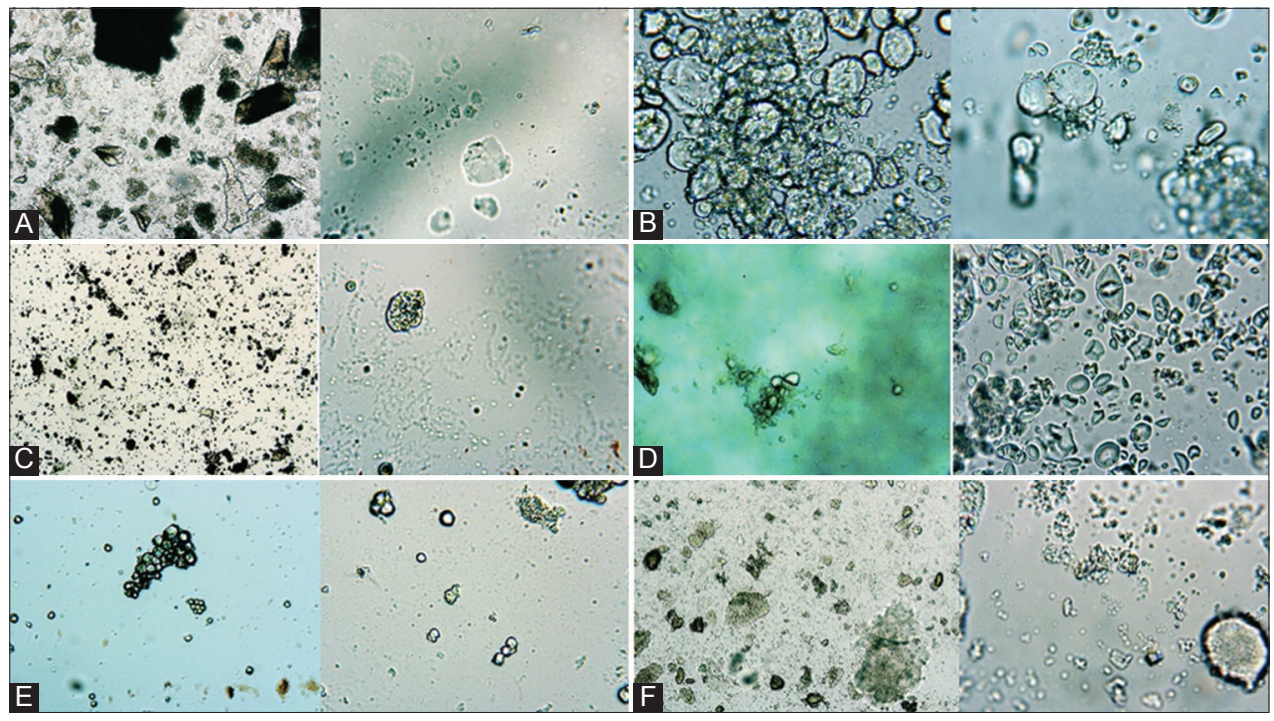

Fig 1. The effect of heating of $2 \%$ starch dispersions of the investigated samples to $75^{\circ} \mathrm{C}$ : A - Amaranth; B - Einkorn; C - Buckwheat; D - Common oat; E - proso millet; F - Quinoa. 
with health promoting features. All studied grains and seeds appeared to contribute to the daily nutritional recommendations, respectively with and appreciable percentage of potassium and phosphorus.

The current findings provide and expand the knowledge of the nutrient profile of the currently selected grains and seeds. The availability of this food composition data will facilitate further nutrition-related studies and will likely encourage the consumption of dishes rich in key nutrients provided by non-refined grains and seeds.

\section{ACKNOWLEDGMENT}

This work was supported by the University of Food Technologies Scientific Research Fund, project 12/18-H.

\section{Authors' contributions}

D.M., R.V., L.K. and A.P. conceived and planned the experiments. D.M., R.V., L.K. and A.P. carried out the experiments. D.M., R.V. and A.P. contributed to the interpretation of the results. D.M. drafted the paper with input from all authors. All authors provided critical feedback and helped shape the final manuscript.

\section{REFERENCES}

AACC. 2000. Method 44-15.02. Moisture Air-oven Methods. American Association of Cereal Chemists International.

Abdel-Aal, E., P. Hucl and F. Sosulski. 1995. Compositional and nutritional characteristics of spring einkorn and spelt wheats. Cereal Chem. 72: 621-624.

Alcázar-Alay, S. and M. Meireles. 2015. Physicochemical properties, modifications and applications of starches from different botanical sources. Food Sci. Technol. (Campinas). 35: 215-236.

AOAC. 2012. Official Method 920.39. Fat (crude) or Ether Extraction in Animal Feed. Official Methods of Analysis. AOAC International, Gaithersburg, MD, USA.

AOAC. 2003. Official Method 942.05. Ash in Animal Feed. Official Methods of Analysis. AOAC International, Washington, DC, USA.

AOAC. 2005. Official method 979.09. Proteins in Grains. Official Methods of Analysis. AOAC International, Washington, DC, USA.

Barreto, D., E. Gutierrez, M. Silva, F. Silva, N. Silva, and I. Lacerda. 2016. Characterization and bioaccessibility of minerals in seeds of Salvia hispanica. Am. J. Plant Sci. 7: 2323-2337.

Becker, R., E. Wheeler, K. Lorenz, A. Stafford, O. Grosjean and A. Betschart. 1981. A compositional study of Amaranth grain. J. Food Sci. 46: 1175-1180.

Beaton, L. 2014. Grain-free pet food: A top trend in the U.S. pet market. Pet Food Ind. 56: 68-70.

Beloshapka, A., R. Buff, G. Fahey and K. Swanson. 2016. Compositional analysis of whole grains, processed grains, grain co-products, and other carbohydrate sources with applicability to pet animal nutrition. Foods. 5(2): 23.

Bernacchia, R., R. Preti and G. Vinci. 2014. Chemical composition and health benefits of flaxseed. Austin J. Nutr. Food Sci. 2: 1045.
Ciolek, A., B. Makarski, E. Makarska and A. Zadura. 2007. Content on some nutrients in some new black oat strains. J. Elementol. 12(4): 251-259.

Demir, M., A. Ünver, D. Arslan, G. Üçok, F. Terlemez and S. Türker. 2015. Characterisation of einkorn (Triticum monococcum L. subsp. monococcum) wheat oil. Qual. Assur. Saf. Crop. 7: 707-712.

Eggum, B., I. Kreft and B. Javornik. 1980. Chemical composition and protein quality of buckwheat (Fagopyrum esculentum Moench). Plant Food Hum. Nutr. 30: 175-179.

Goyal, A., V. Sharma, N. Upadhyay, S. Gill and M. Sihag. 2014. Flax and flaxseed oil: An ancient medicine and modern functional food. J. Food Sci. Technol. 71: 62-70.

Graf, B., P. Rojas-Silva, L. Rojo, J. Delatorre-Herrera, M. Baldeón and I. Raskin. 2015. Innovations in health value and functional food development of quinoa (Chenopodium quinoa Willd.). Compr. Rev. Food Sci. Food Saf. 14(4): 431-445.

Guzman-Maldonado, S. and O. Paredes-Lopez. 1998. Functional products of plant indigenous to Latin America amaranth and quinoa, common beans and botanicals. In: Mazza G, editor. Functional Foods Biochemical and Processing Aspects. Technomic Publishing Company, Pennsylvania. pp. 293-328.

Halima, N., R. Saad, B. Khemakhem, I. Fendri and S. Abdelkafi. 2015. Oat (Avena sativa L.): Oil and nutriment compounds valorization for potential use in industrial applications. J. Oleo Sci. 64: 915-932.

Hlinková, A., A. Bednárová, M. Havrlentová, J. Šupová and I. Čičová. 2013. Evaluation of fatty acid composition among selected amaranth grains grown in two consecutive years. Biologia. 68: 641-650.

Hoover, R. and S. Senanayake. 1996. Composition and physicochemical properties of oat starches. Food Res. Int. 29: 15-26.

Hung, P., T. Maeda and N. Morita. 2006. Waxy and high-amylose wheats characteristics, functionality and uses. Trends Food Sci. Technol. 17: 448-456.

Ikeda, S. and Y. Yamashita. 1994. Buckwheat as a dietary source of zinc, copper and manganese. Fagopyrum. 14: 29-34.

ISO 12966-22017. 2017. Animal and Vegetable Fats and Oils Gas Chromatography of Fatty Acid Methyl Esters - Part 2 Preparation of Methyl Esters of Fatty Acids. International Organization for Standardization, Geneva, Switzerland.

Kalinova, J. and J. Moudry. 2006. Content and quality of protein in proso millet (Panicum miliaceum L.) varieties. Plant Foods Hum. Nutr. 61: 43.

Kim, S., H. Choi, D. Kang and H. Kim. 2012. Starch properties of native proso millet (Panicum miliaceum L.). Agron. Res. 10: 311-318.

Krumina-Zemture, G. and I. Beitane. 2017. Fatty Acid Composition in Buckwheat (Fagopyrum esculentum M.) Flours and their Extruded Products. Proceedings of the $8^{\text {th }}$ International Scientific Conference Rural Development, Kaunas, Lithuania. pp. 66-69.

Langton, M. and A. Hermansson. 1989. Microstructural changes in wheat starch dispersions during heating and cooling. Food Microstruct. 8: 29-39.

Leng, G., R. Adan, M. Belot, J. Brunstrom, K. De Graaf and S. Dickson. 2017. The Determinants of Food Choice. In: Proceedings of the Nutrition Society). Cambridge University Press, Cambridge. pp. 83-90.

Li, G. and F. Zhu. 2017. Quinoa starch: Structures, properties, and applications. Carbohydr. Polym. 181: 851-861.

Li, J., T. Vasanthan, R. Hoover and B. Rossnagel. 2004. Starch from 
hull-less barley: IV Morphological and structural changes in waxy, normal and high-amylose starch granules during heating. Food Res. Int. 37: 417-428.

Lindeboom, N., P. Chang, K. Falk and R. Tyler. 2005. Characteristics of starch from eight quinoa lines. Cereal Chem. 82: 216-222.

Liu, K. 2011. Comparison of lipid content and fatty acid composition and their distribution within seeds of 5 small grain species. J. Food Sci. 76: 334-342.

McEvoy, C., N. Temple and J. Woodside. 2012. Vegetarian diets, low-meat diets and health: A review. Public Health Nutr. 15: 2287-2294.

Mohammadkhani, A., F. Stoddard and D. Marshall. 1999. Amylose content in segregating populations of einkorn, emmer, and rye. Starch-Starke. 51: 66-73.

Nedeljković, N., M. Sakač, A. Mandić, D. Psodorov, D. Jambrec and M. Pestorić. 2014. Rheological properties and mineral content of buckwheat enriched wholegrain wheat pasta. Chem. Ind. Chem. Eng. Q. 20: 135-142.

Nitrayová, S., M. Brestenský, J. Heger, P. Patráš, J. Rafay and A. Sirotkin. 2014. Amino acids and fatty acids profile of chia (Salvia hispanica L.) and flax (Linum usitatissimum L.) seed. Potravinarstvo. 8: 72-76.

Noisuwan, A., Y. Hemar, J. Bronlund, B. Wilkinson and M. Williams. 2007. Viscosity, swelling and starch leaching during the early stages of pasting of normal and waxy rice starch suspensions containing different milk protein ingredients. Starch/Staerke. 59: 379-387.

Palombini, S., T. Claus, S. Maruyama, A. Gohara, A. Souza and N. de Souza. 2013. Evaluation of nutritional compounds in new amaranth and quinoa cultivars. Food Sci. Technol. (Campinas). 33: 339-344.

Pilat, B., D. Ogrodowska and R. Zadernowski. 2016. Nutrient content of pufed proso millet (Panicum miliaceum L.) and amaranth (Amaranthus cruentus L.) grains. Czech J. Food Sci. 34: 362-369.

Präger, A., S. Munz, P. Nkebiwe, B. Mast and S. Graeff-Hönninger. 2018. Yield and quality characteristics of different quinoa (Chenopodium quinoa Willd.) cultivars grown under field conditions in Southwestern Germany. Agronomy. 8: 197.

Rachoń, L., G. Szumiło, M. Brodowska and A. Woźniak. 2015.
Nutritional value and mineral composition of grain of selected wheat species depending on the intensity of a production technology. J. Elem. 20: 705-715.

Repo-Carrasco-Valencia, R. and L. Serna. 2011. Quinoa (Chenopodium quinoa, Willd.) as a source of dietary fiber and other functional components. Food Sci. Technol. (Campinas). 31: 225-230.

Stamatovska, V., G. Nakov, Z. Uzunoska, T. Kalevska and M. Menkinoska. 2018. Potential use of some pseudocereals in the food industry. Appl, Res. Tech Technol Educ. 6(1): 54-64.

Stockley, L., M. Rayner and A. Kaur. 2008. Nutrient Profiles for use in Relation to Food Promotion and Children's Diet: Update of 2004 Literature Review. Food StandardAgency, London. Available from: http//www.food.gov.uk/healthiereating/advertisingtochildren/ nutlab/nutprofilereview/nutprofilelitupdatedec07. [Last retrieved on 2019 Jan 31].

Svegmark, K. and A. Hermansson. 1991. Distribution of amylose and amylopectin in potato starch pastes: Effects of heating and shearing. Food Struct. 10: 117-129.

Tester, R. and W. Morrison. 1990. Swelling and gelatinization of cereal starches. I. Effects of amylopectin, amylose and lipids. Cereal Chem. 67: 551-557.

Van Hung, P., T. Maeda and N. Morita. 2009. Buckwheat starch Structure and characteristics A review. Eur. J Plant Sci. Biotechnol. 3: 23-28.

Verhagen, H. and H. Van Den Berg. 2008. A simple visual model to compare existing nutrient profiling schemes. Food Nutr. Res. 52.

Vermier, I. and W. Verbeke. 2006. Sustainable food consumption :Exploring the consumer "attitude behavioral intention" gap. J. Agric. Environ. Ethics. 19: 169-194.

WHO. 2010. Nutrient Profiling: Report of a WHO/IASO Technical Meeting. London, United Kingdom, 4-6 October 2010. Available from: https//www.who.int/nutrition/publications/profiling/WHO_ IASO_report2010.pdf. [Last retrieved on 2019 Jan 25].

Wu, G., C. Morris and K. Murphy. 2017. Quinoa starch characteristics and their correlations with the texture profile analysis (TPA) of cooked quinoa. J. Food Sci. 82: 2387-2395.

Zhu, F. 2015. Composition, structure, physicochemical properties, and modifications of cassava starch. Carbohydr. Polym. 122: $456-480$ 